\title{
Care of photographs
}

\author{
By Gary Albright
}

\section{The right environment and proper storage are critical}

"Behold thy portrait! — day by day,

I've seen its features clie;

First the moustachios go away,

Then off the whiskers fly.

That nose I loved to gaze upon,

That bold and manly brow,

Are vanish id, fled, completely gone

Alas! Where are they now?

So lamented a poet in an 1847 issue of Punch less than 10 years after the invention of photograply. The same could be written about many of today's photographic images. People have been concerned about the permanence of photographs for more than 150 years. Over that time, dozens of photographic processes have been used. Each has its own unique deterioration characteristics and, therefore, its own specific storage and exhilsition needs. However, there are common factors affecting the permanence of all photographs. By controlling these factors, the deterioration of a photograph can be slowed, and its longevity greatly enhanced.

\section{Control temperature and relative humidity}

Control of temperature and relative humidity (RH) is critical to the preservation of photograph collections. Heat accelerates deterioration: the rate of chemical deterioration of most photographic materials is approximately doubled with each $10^{\circ} \mathrm{F}$ increase in temperature. High relative humidity provides the moisture necessary for harmful chemical reactions leading to much of the facting, discoloration, and silver mirroring visible in photograph collections. High relative humidity in combination with high temperature encourages mold growth and insect activity. Extremely low relative humidity may lead to clesiccation and embrittlement of certain photographic materials, as well as curling of photographs or flaking of glass plate emulsions.

Excessive fluctuations in temperature and relative humidity are also damaging. These may lead to structural damage within photographs, such as cracking of emulsions or warping of photographic supports.

Temperature should be maintained at $70^{\circ} \mathrm{F}$ or below. In general, the lower the temperature, the better. An often recommended compromise between storage needs and staff comfort is $65^{\circ}-70^{\circ} \mathrm{F}$. Areas used exclusively for storage should be kept at a lower temperature. Relative humiclity for a mixed collection of photographs should be maintained between 30 percent and 50 percent with fluctuations less than 10 percent a day. Storage at the low end of the RI range rather than at the ligher end can significantly inprove the long-term stability of several photographic processes. Cold storage is often recommended for particularly vulnerable materials such as color photographs, nitrate film. or safety film. When materials are taken out of cold storage, they should be placed in a plastic bag and allowed to acclimate to room conditions before use. This avoids potential condensation and water on the cold surfaces of the materials

Temperature and humidity can be controlled using various forms of climate-control equipment. When such equipment is not available, there are still simple measures that can be taken to moderate environmental conditions. Avoid 
using attics (too hot) or basements (too damp) for storage areas. Often an interior room or closet offers the best environment. Collections should be kept off the floor, where they are more likely to be damaged by insects or water. Don't hang or store photographs on exterior walls, in bathrooms, or over heat sources such as fireplaces, radiators, or heating vents Keep heat low in the winter, and encourage the staff and visitors to wear warm clothing Seal windows and doors to minimize exchange of outside air. Store photographs in folders, boxes, or calbinets; this moderates the effects of environmental fluctuations. The use of air conditioners, dehumidifiers, and humidifiers can also be helpful. However, make sure that such equipment is improving conditions and not causing them to worsen. For example, airconditioning can actually raise relative humidity under certain circumstances.

\section{Control air pollution and dirt}

Pollutants and particulate matter can damage photographs, causing fading or abrasion. Air purity is especially a concern in an urban environment.

Controlling air quality is difficult. Ideally, air entering a storage or exhibition area should be filtered and purified. Dust should be kept to a minimum. Gaseous pollution can be removed by chemical filters or wet scrubbers. Particulates can be mechanically filtered. Good air circulation is also necessary. Make sure air intake vents are not located near loading docks where trucks idle. Keep exterior windows closed when possible. Also, minimize interior sources of harmful gases. These include photocopying machines, many construction materials, paint fumes, cardboard, carpets, and janitorial supplies. Metal cabinets are preferred over wood, as wood often generates harmful peroxides. Finally, keep photographs in archivalquality enclosures. Enclosures keep dirt off objects and may help decrease the effects of pollutants. Enclosures containing activated charcoals and molecular traps have recently become available and appear to be effective in this regard.

\section{Control light levels}

Light causes embrittlement, yellowing, and fading in photographs. Light damage is cumulative and usually irreversible. Direct sunlight is the most harmful light source; incandescent (tungsten) lighting is generally preferred to fluo- rescent. However, all forms of light are damaging and should be moderated.

Do not place valuable photographs on permanent display. Use copies whenever possible (color laser copies are an inexpensive, readily accessible alternative) and keep light levels as low as possible. Avoid hanging photographs where they will be exposed to daylight, especially direct sunlight, or to unfiltered fluorescent lights. Both of these light sources generally give off high amounts of damaging ultraviolet (UV) light. UV-absorbing sleeves can be used to filter out damaging rays from fluorescent tubes, and UV-absorbing sheets can be placed over windows or in frames. Also, lowUV-emitting bulbs are now available. Be aware that certain types of photographs are much more susceptible to light damage than others. Most color photographs fade rather quickly on display, while contemporary fiber-base blackand-white prints are essentially stable. Exhibition of 19th-century photographs should be limited and carefully controlled.

\section{Control handling}

Fingerprints can cause chemical damage to photographs, resulting in bleaching or silver mirroring. Careless handling can cause physical damage such as abrasion, tears, or breakage. Use clean gloves or clean, dry hands whenever photographs are handled. Don't touch photographic emulsions. Handle photographs carefully. Proper enclosures (sleeves, albums) provide protection from fingerprints and physical support to protect against abrasion or breakage. Whenever possible, avoid handling altogether by providing users with photographic duplication or photocopies.

If photographs must be labeled, labeling should be done on the reverse along the edge. In most cases, ordinary lead pencils are recommended. Where lead pencils do not work (such as with RC prints), black india ink is recommended. Koh-I-Noor Black Rapidomat Ink No. 30740-F in a hollow-point technical pen appears to work particularly well.

\section{Control storage systems}

Proper storage materials are essential for the long-term stability of photographs and negatives. They provide much-needed physical support and protection for fragile objects, and at the same time act as a barrier between the photograph and a potentially unstable environment. It is of utmost importance that storage materi- 
als be unreactive to the photographic material. Much damage has been clone in the past through the use of reactive materials such as acidic groundwood paper sleeves, rubber bands, paper clips, pressure-sensitive tapes, and staining adhesives such as rubber cement or animal glue.

All enclosures used to house photographs should meet the specifications provided in the American National Standards Institute (ANSI) Stanclard IT9.2-1991, and should have passed the Photographic Activity Test (PAT) as specified in ANSI NAPM IT9.16-1993. The first standard provides specifications on enclosure formats, papers, plastics, adhesives, and printing inks. The PAT has two components: a test to detect image fading resulting from harmful chemicals in enclosures, and a test to detect staining reactions between enclosures and gelatin. Consumers should contact their suppliers to see if their products have passed the PAT.

When storing photograplss it is best for each object to have its own enclosure. This reduces damage to the photograph by provicling it with physical protection, support, and isolation from any damaging components of other photographs. Prints and negatives should not be in contact with each other in the same enclosure. Acceptable enclosures may be made of either paper or plastic.

\section{Paper enclosures:}

- are opaque. This protects objects from light, but may result in increased handling for viewing.

- are porous. This protects the object from the accumulation of moisture and detrimental gases.

- act as a buffer against changes in humidity.

- are available in buffered and nonbuffered stock. Choosing between the two is not the crucial issue it was once thought to be. In most cases conservators prefer nonbuffered material, but buffered enclosures are usually recommended for storing nitrate negatives and early safety film.

- should not be made of kraft or glassine paper

\section{Plastic enclosures:}

- are transparent. Photographs can be viewed without removal from the enclosure, thus reducing handling.
- can trap moisture and cause ferrotyping (sticking, with a resultant glossy area).

- should be made of uncoated polyester, polypropylene, or polyethylene. Soft polypropylene and low-density polyethylene (both used in ring-binder storage pages) have additives or coatings that cannot be properly evaluatted.

- should not be made from polyvinylchloride (PVC).

- should not be used to store nitrate or older saffety film negatives, as this will hasten their deterioration.

Avoici using aclhesives that may cause chemical damage. Aclhesives that are particularly damaging include rubber cement and the self-stick "magnetic" pages of photograph albums. Also, avoid pressure-sensitive tapes and damaging fasteners such as paper clips and rubler bands. Because adhesives can be problematic, photographs that are stored in paper envelopes should be positioned with their emulsion away from the seam. Also. seams should be on the sides of the enclosure, not through the center.

Once materials have been properly housed in window mats, folders, sleeves, or envelopes, they should be stored in calninets or boxes of archival quality. Horizontal storage is preferable for many photographic prints and for oversized photographs. It provides overall support to the images and avoids the possibility of mechanical damage such as bending. Vertical storage is often preferred for negative collections, but it can also be very effective for certain photographic print collections. Vertical storage is often more efficient and may make access to a collection easier. Glass plate negatives require vertical storage in order to prevent breakage. However, very large plates should be supported horizontally. When using vertical storage, protect materials by placing them in acid-free folclers. These folders should then be stored in either hanging files or document storage boxes. Boxes should be housed on metal shelves or in metal cabinets.

Where possible, materials of similar size should be stored together. Mixing of sizes can cause abrasion or breakage. Regardless of the size of the objects, all enclosures within a box should be the same size, should be larger than the materials stored in them, and should fit the box or drawer. Boxes and files should not be over crowcled. 


\section{A CLASSIC PARTNERSHIP}

\section{SILVerPlatter INFORMATION}

\section{THE MODERN LANGUAGE ASSOCIATION}

SilverPlatter Information and the Modern Language Association of America have joined together to create a superior MLA International Bibliography database - the valuable information you rely upon combined with easy-to-use retrieval software for precise search results.

The Timeless Database

Long recognized as a fundamental research tool in the humanities, the MLA International Bibliography database contains I.3 million bibliographic citations focusing on research in literature, language, linguistics, and folklore. Users enjoy access to more than 4,000 sources of information about:

- Literature: American to Zambian

- Genres from poetry and drama to correspondence and oral traditions

- Literary theories from feminist to postcolonial

- Manuscript studies, folk poetry, psycholinguistics, popular culture, and much more!

\section{Powerful Presentation}

SilverPlatter's effective portrayal of the MLA Bibliography thesaurus tree allows for precise searching of concepts, theories, and genres, using single or multiple criteria. SilverPlatter's award-winning search and retrieval software allows both expert and novice users to obtain meaningful search results easily, making the MLA International Bibliography on SilverPlatter the preferred database.

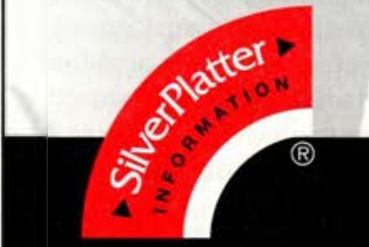

SilverPlatter Information, Inc. 100 River Ridge Drive Norwood, MA 02062 Fax: $617-769-8763$ URL: http://www.silverplatter.com
Available on CD-ROM, Hard

Disk, or Internet Subscription.

For a free 30-day trial or

more information on the

MLA International

Bibliography

on SilverPlatter, please call 800-343-0064 or email

SilverPlatter at jogisilverplatich.com

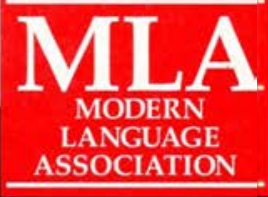

Modern Language Association of America 10 Astor Place New York, NY 10003-698I 